\title{
Occupational asthma after inhalation of dust of the proteolytic enzyme, papain
}

\author{
JAMES MILNE and SOL BRAND \\ Industrial Hygiene Division, Melbourne, Victoria, Australia
}

\begin{abstract}
Milne, J. and Brand, S. (1975). British Journal of Industrial Medicine, 32, 302-307. Occupational asthma after inhalation of dust of the proteolytic enzyme, papain. Papain is a proteolytic enzyme widely used by biochemists. In experiments on animals papain has been shown to cause emphysema either when they inhaled a single small dose or after intratracheal inhalation. Four food technologists were occupationally exposed to heavy concentrations of papain dust in air. Subjects 1 and 2 developed an immediate acute asthmatic reaction, and symptoms of obstructive airways disease persisted for some months while each remained in the same working area, presumably exposed to small gradually diminishing amounts of residual papain dust. Tests of respiratory function were carried out on all four subjects $1 \frac{1}{2}$ years later and showed in subjects 1 and 3 minimal abnormality of bronchial reactivity and of ventilation distribution. Review of the literature reveals only two reports of asthma resulting from papain inhalation, although its antigenic and skin sensitizing qualities have been known and described for many years. It seems remarkable that a substance such as papain, shown to be a potent cause of lung damage in experimental animals, should have produced so little evidence of abnormality in our subjects after considerable exposure. Follow-up ventilatory function tests may cast further light on this but we postulate that the asthmatic response may be biologically protective and those lacking this reaction could later develop emphysema as a long-term outcome.
\end{abstract}

Technological advances and increasing affluence have facilitated the gradual mechanization of household tasks on a widening scale throughout the community. Concurrently, chemical and biochemical ingenuity has provided new and different methods of cleaning for the housewife. Among the latest products for use in home washing machines are detergents employing proteolytic enzymes. Gandevia (1970) remarked on the asthmatic manifestations that can occur after occupational inhalation of these bacterial proteolytic enzyme extracts as powder and as dust.

Another proteolytic enzyme widely used in a different milieu, by both research and industrial biochemists, is papain. Inhalation of this enzyme is an established cause of emphysema in experimental animals (Gross et al., 1965). Considerable interest was aroused, therefore, when it became known that, in the course of an industrial research project, inhalation of papain had caused an acute episode of breathlessness and wheezing in two people.

\section{Review of the literature}

Papain is a sulphydryl protease in a single polypeptide chain of molecular weight 23000 . The chain was shown by Drenth et al. (1968), using a three dimensional $x$-ray study, to be folded into two distinct parts divided by a cleft. They stated that the active enzymatic site lies at the surface of the cleft.

Arnon and Shapira (1967) used selective fractionation of rabbit antiserum to study antibodies to papain and compared various antibody preparations on the basis that these could inhibit the 
enzymatic activity of papain and their relative reactivity in the precipitin reaction. It was shown that the rabbit antibody spectrum is heterogeneous, that is, some antibodies inhibited enzymatic activity whereas others, although precipitating well with the enzyme, did not inhibit proteolytic activity.

Reports of pulmonary effects in humans are rare. Beecher (1951) discussed the case of a 'druggist' who was sensitive to 'digestive ferments', developed asthma and rhinitis as a result, and exhibited marked skin sensitivity to papain. Beecher mentioned three other cases known to him who developed asthma due to Caroid, a proprietary preparation of papain.

Osgood (1945) reported the case of a woman who was extremely sensitive to papain who developed asthma on exposure to a tooth powder containing the enzyme. She recovered when all traces of the powder were removed from the home. Later, on intradermal testing, she suffered what appears retrospectively to have been an anaphylactic response, with mental confusion, pallor, sweating, vomiting, labouring respirations, impalpable peripheral arterial pulse, and loss of consciousness. She recovered consciousness about three hours later, but had severe urticaria for the following five days. Superficial necrosis occurred at the test sites, followed by subcutaneous nodules persisting for four months. Osgood made a careful search of the literature and could find no other reference to asthma from papain alone, apart from Beecher's cases.

Hwang and Ivy (1951) reviewed the literature relating to papain up to that date, and listed about 300 references. They noted that the antigenicity of papain was shown, among other things, by anaphylactic reactions in sensitized guinea-pigs. They listed all the clinical reports on humans available in the literature and it is noteworthy that the only cases of asthma found by them to be due solely to papain sensitivity were those of Osgood and Beecher. We have been unable to trace any other cases apart from our own.

However, apart from its bronchospasmodic effect in humans, there is experimental evidence that papain has also caused pulmonary emphysema in animals (Gross et al., 1964).

Experiments were carried out on normal and silicotic rats (Gross et al., 1965), and later an 'interspecies gradation in the severity of the emphysema' was shown (Gross et al., 1968). Guinea-pigs and rats both developed emphysema after the intratracheal instillation of papain, and it should be noted that in each animal species, a single intratracheal instillation of approximately $1 \mathrm{mg}$ papain was sufficient to produce emphysematous change of a pattern exactly similar to that commonly found in humans.

Goldring, Greenburg, and Ratner (1968) employed a modification of the method of Gross, using
Syrian hamsters. Instead of instilling papain directly into the trachea of the experimental animal, they sought complete involvement of all lung lobes by using the papain as an aerosol of particle size less than $5 \mu \mathrm{m}$, small enough to reach the alveoli. They were able to produce emphysema in all lobes of the lungs of all 12 animals and they stated that 'The lesions are panacinar and similar to those seen in the human lung'. Since they used papain in aerosol form and the animals were exposed in a plastic exposure chamber, their experimental conditions were more comparable with our industrial situation than those of Gross et al. $(1964,1965,1968)$ who employed intratracheal instillation. Goldring et al. (1968) also found that all their experimental animals had asthma. They noted that 'within 18 hours after exposure, all 12 of the treated animals exhibited signs of severe respiratory distress, laboured breathing, wheezing, rales, and increased salivation'. All papain-exposed animals recovered from the acute respiratory distress within a week and the exposure continued for at least another 50 days in all cases, and up to 120 days in some.

\section{Case reports}

\section{Case 1}

A 27-year-old female analytical chemist had suffered from occasional attacks of bronchitis and bronchial asthma from the age of about 7 to 15 years. She had always noticed a tendency to wheeze on exertion or on laughing. There was a family history of hay fever. Her general health was good and she was free of asthma until the day in question when, while working in the laboratory, she noticed a 'fine dusty smoke-like effect' in the corridor. Unknown to her at that time, this was papain dust from a sifting process as part of a research project being carried out for the first time in a nearby room. Over the next 10 to 15 minutes she noticed eye irritation followed by increasing nasal secretion, and then the rapid, almost abrupt onset of asthma which within a further 10 minutes had become so distressing that her chest ached from the effort of breathing and she wheezed heavily. She had to cease work and was taken by ambulance to a nearby hospital where she was given treatment which included an injection of adrenaline. About $1 \frac{1}{2}$ hours later her symptoms had considerably abated and she was allowed to go home.

Some days later she consulted one of us (SB) and was asked to bring some papain to make a preparation for the testing of skin sensitivity. In the subsequent handling of the small amount of papain that was necessary she was not exposed to a visible powder but she experienced an itchy irritation of the eyes and a running nose which lasted three days. Skin tests were carried out using a scratch method. The crude papain granules had been milled to a fine powder for the factory process and a sample of this powder, as used by the operatives, was obtained. Coca's solution was used as a diluent, and to $0.02 \mathrm{ml}$ of this solution was added sufficient papain powder to make a smooth paste. A scratch $(3-5 \mathrm{~mm}$ in length) was made on the woman's arm without drawing 
blood so as to expose the superficial layers of epidermis. The paste was applied gently to the scratched area and a control test using diluent alone was concurrently performed. The area was continuously observed over a period of 10 minutes and an unequivocally positive reaction appeared rapidly. This consisted of an urticarial weal approximately $9 \mathrm{~mm}$ in diameter, an actively developing pseudopodia about $20 \mathrm{~mm}$ in length, and erythema about $60 \mathrm{~mm}$ in diameter. The control test was negative.

Using the same technique, skin tests were performed on the patient to assess sensitivity to common grass pollens, animal hair, and house dust. All these were negative.

Skin tests were also performed in the same way on another 100 consecutive subjects to assess their sensitivity to the papain powder, and none showed a positive reaction.

No wheeze occurred when this patient handled the sample of powder, or at the time of the skin test, but that night she experienced an attack of asthma. A few days later when she returned to work in the laboratory, she noticed wheezing and sometimes breathlessness on effort. This gradually disappeared over the succeeding 12 months except for about three months after the acute episode when she was away from the laboratory for a period of several weeks and lost all respiratory symptoms. When she returned to work she again became aware of exertional wheeze. After the gradual abatement of symptoms, her general health returned to what she describes as its normal state.

The firm had discontinued the use of papain in the area in which she worked by the time she returned to the laboratory. Apart from residual dust from the original episode, she was subjected to no further occupational source of papain exposure and she has never used papain in her job since.

\section{Case 2}

A 32-year-old male industrial research chemist had no personal history of allergy, asthma, or hay fever but there was a family history of hay fever. He usually worked in the same factory as the analytical chemist, but in a different building. He was involved in a research project concerning the use of papain for proteolysis in a proprietary food mix. The project required the grinding of relatively large lumps of papain and then sifting it.

On the day in question he was working in the same room as the grinding machine. The room was about $6 \times 7 \times 3 \mathrm{~m}$ and he worked about 2 to $3 \mathrm{~m}$ from the grinder. About five minutes after the grinding began he began to sneeze. About 10 minutes later he started to cough and soon after he noticed that he was wheezing. He was not conscious of seeing or smelling anything in the air. His chest condition proved too much for him to remain where he was, so he went to another building and over the next three hours his symptoms subsided until he was just aware of some slight residual irritation in his chest but had no real discomfort.

Unknown to him, however, sifting was to be carried out in this second building. That day the powder arrived and when sifting started, as previously described in case 1, a fine dust like a smoke appeared in the corridor. Although this was on the floor below the one on which he was now working, the cough returned soon after and was followed by a marked wheeze. He was breathless and distressed and was taken to the same nearby hospital, where his symptoms abated after treatment.

Skin tests (scratch method) were carried out in the same way as described for case 1 . These were negative to common grass pollens, animal hair, and house dust; but the papain test was unequivocally positive producing an urticarial weal of similar dimensions to that described in the previous patient, and that night he experienced an attack of asthma.

In the succeeding two months he noticed that any exertion that was sufficient to make him breathless also made him wheeze. He then went on holiday and although he spent about three weeks in quite severe exertion he did not wheeze during this period. On his return to work the wheeze was noted to be present again during exertional dyspnoea, but it slowly abated and finally disappeared about a year after the original attack. The industrial process was discontinued after this patient's acute episode of asthma dyspnoea and he was no longer exposed to papain, apart from the possibility of residual dust in his working area.

Asthma occurred in the two cases described above. Of others similarly exposed, two who did not wheeze were later assessed by lung function studies at the same time as the two asthmatics. Their case histories are briefly detailed.

Although it was clearly recognized that these were not matched controls, nevertheless they were the only controls available; hence it was considered worthwhile to assess their pulmonary function because this represented the only method available to investigate the differences in pulmonary physiology between the two patients with an asthmatic-type reaction and two other subjects who had been similarly exposed but did not exhibit symptoms.

\section{Case 3}

A 39-year-old man was in charge of the hammer mill in which the crude papain was ground from about popcorn size to fine powder. He had handled crude papain before, and on this occasion was exposed without respiratory protection for about $1 \frac{1}{2}$ hours twice weekly for three weeks to papain dust in the air, described as a fine cloud around the mill.

He noticed a running nose at first but this soon disappeared. He has had no further symptoms or signs and has handled papain since then without incident. His general health is good and he has no history of allergy or asthma.

\section{Case 4}

A 24-year-old man who worked under similar conditions to the previous man recalled having had a mild nonproductive cough and some tiredness at the time of his exposure to papain. He has not handled papain since. He has no history of asthma or allergy. His general health is good.

\section{Respiratory function}

Assessment of respiratory function was performed 17 months after exposure. Ventilatory capacity was measured using standard spirometric techniques. 
TABLE

Pulmonary Function Studies

\begin{tabular}{|c|c|c|c|c|c|c|c|}
\hline \multicolumn{3}{|c|}{ Respiration } & \multicolumn{4}{|c|}{ Subject no. } & Normal values \\
\hline 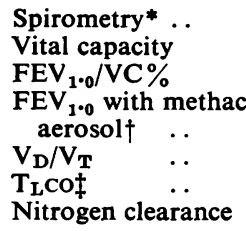 & $\begin{array}{l}. . \\
. \\
\text { choline } \\
. . \\
. \\
. \\
.\end{array}$ & $\begin{array}{l}. . \\
\cdots \\
\cdots \\
\cdots \\
\cdots \\
\cdots \\
\cdots\end{array}$ & $\begin{array}{c}1 \\
108 \\
89 \\
-29 \% \\
0.22 \\
13 \cdot 2 \\
\text { Alinear }\end{array}$ & $\begin{array}{c}2 \\
96 \\
85 \\
-6 \% \\
0 \cdot 38 \\
44 \\
\text { Linear }\end{array}$ & $\begin{array}{c}3 \\
100 \\
70 \\
-18 \% \\
0 \cdot 24 \\
32 \cdot 2 \\
\text { Alinear }\end{array}$ & $\begin{array}{c}4 \\
83 \\
87 \\
-5 \% \\
0 \cdot 28 \\
56 \\
\text { Linear }\end{array}$ & $\begin{array}{c}-15 \% \\
0 \cdot 33 \\
15\end{array}$ \\
\hline
\end{tabular}

*Vital capacity as percentage of predicted (Needham, Rogan, and McDonald, 1954).

$\dagger$ Expressed as percentage change of initial value

$\mp \mathrm{ml} / \mathrm{min}$ per $\mathrm{mm} \mathbf{H g}$

Non-specific bronchial reactivity was assessed using methacholine aerosol challenge by techniques previously described (Cade and Pain, 1971). A multibreath nitrogen washout test with the subject breathing oxygen was used to assess ventilation maldistribution (Fowler, Cornish, and Kety, 1952). Linearity in the plot of log expired nitrogen concentration against time was taken as evidence of normal ventilation distribution. The physiological dead space/tidal volume ratio $\left(V_{D} / V_{T}\right)$, an index of ventilation/blood flow relationships, was calculated from simultaneous measurements of carbon dioxide tension in the expired air (Godart Pulmoanalyser) and arterial blood (Severinghaus $\mathrm{PcO}_{2}$ electrode) during a two minute collection period with the subjects semirecumbent. The dead space was corrected for apparatus dead space. Diffusing capacity of the lungs for carbon monoxide $\left(\mathrm{T}_{L} \mathrm{CO}\right)$ was assessed by the steady-state technique of Holland and Blacket (1958).

The ventilatory capacity was within normal limits in all subjects (see Table). Methacholine challenge revealed an abnormally large reduction in ventilatory capacity in subjects 1 and 3 , indicating heightened bronchial reactivity. These two people also had evidence of maldistribution of ventilation before methacholine challenge. In no subject was the $V_{D} / V_{T}$ ratio significantly raised. In subject 1 , the diffusing capacity was at the lower limit of normal.

Thus, at that stage, the two subjects who developed asthma were functionally similar to the two asymptomatically exposed subjects. The subject who had a history of asthma (subject 1) showed features commonly found in interval asthmatics (Cade and Pain, 1973). It is of interest that subject 2 appeared not to have retained heightened bronchial reactivity, assuming he had an abnormal bronchial responsiveness at the time of clinical symptoms, a feature mentioned by Mitchell (1970) in relation to asthma induced by exposure to Western Red Cedar.

The tests performed do not allow any positive statement to be made on the development of emphysema. Follow-up long function tests with measurements of static deflation pressure-volume relationships will obviously be of great importance.

\section{Discussion}

Occupational asthma due, not to papain, but to other proteolytic enzymes of bacterial origin has recently received considerable attention. The first description was by Flindt (1969) who stated that: 'although primary irritant effects may have occurred, the severe and sometimes prolonged breathless attacks in most of those investigated were thought to have been due to allergic mechanisms'. He noted the dangers of handling the enzyme extracts of $B$. subtilis as a dry discrete powder. Two sentences in his paper seem particularly apposite to the conditions obtaining in our cases, namely

'When disturbed, fine airborne dust is liberated which is capable of contaminating areas beyond those immediately adjacent to the source, and which may not settle for several hours. Even then, further disturbance can result ... which will lead to the dust becoming airborne again; once more capable of causing illness'.

Immediately after Flindt (1969) is a paper by Pepys et al. (1969) who employed bronchial challenge by experimental inhalation of the $B$. subtilis enzyme in three workers and found that asthmatic reactions resulted.

It seems reasonable to assume that, after the original heavy exposure, the working conditions described in our cases of occupational asthma were such as to cause small gradually diminishing amounts of residual papain dust to become recurrently airborne. The persistence and slow subsidence of symptoms over a period of many months in each case could then be presumed to be caused by recurrent bronchial challenge from the industrial environment. 
We felt it inadvisable to attempt deliberately to reproduce the bronchospasm by bronchial challenge in a respiratory physiology unit, bearing in mind the profound original asthmatic attacks, the marked skin sensitivity, and the nocturnal exacerbations after skin testing.

A relationship with the possible development of emphysema must be considered in those inhaling proteolytic enzymes, especially papain, because of the finding of Gross et al. (1965) who reported emphysema within six hours of one instillation intratracheally into guinea-pigs. Gandevia and Mitchell (1971) drew attention to this possibility and in a study of 36 men they found evidence of loss of elastic recoil in the lungs of a highly exposed group. They go on to say that they 'conclude that the observed loss of elastic recoil is attributable to occupational exposure to proteolytic enzymes, and ... believe it is likely to be permanent. In the absence of severe longstanding and chronic airways obstruction, .... the only known and generally accepted cause of loss of elastic recoil is emphysema'.

In the light of the foregoing, and on the evidence provided by our four subjects, one may speculate as to whether the inhalation of papain might have produced emphysematous changes. The answer at this juncture cannot be other than conjectural. It is our intention with the co-operation of the industry, to conduct long-term follow-up studies. Our present results indicate some minimal abnormality in nitrogen washout, pointing to some change in the small airways, but we cannot relate this specifically to papain inhalation.

It seems unlikely that these changes in nitrogen washout are related to inhalation of papain since they are minimal and differ in case incidence from the cases of acute asthma. It is remarkable that there is so little evidence of abnormality resulting from severe exposure to a substance that has been shown to have a potent effect on animal lungs.

Experiments with animals by Gross et al. (1968) showed that guinea-pigs 'apparently become sensitized after the first instillation ... . Some died with findings characteristic of anaphylactic shock when a second dose was injected'. The first dose produced emphysema in all animals, which may indicate that the first effect of the enzyme on the lungs of the animal is proteolytic and that this also provides primary sensitization so that a second instillation may cause anaphylaxis.

If we assume that it is the proteolytic effect of papain which produces emphysema by tissue destruction, the presence of proteolysis-inhibiting antibodies would then appear to prevent the occurrence of emphysema.

From the work of Arnon and Shapira (1967) one may conclude that at least some rabbit antibodies will inhibit proteolysis. It would seem probable that a similar antibody spectrum exists in human serum. Hence an antigen-antibody reaction to papain in humans, although producing asthma, could also imply less chance of emphysema occurring in the immune individual. Goldring et al. (1968) would appear to contradict this hypothesis but the exposure time in their study was prolonged. Further studies including long-term follow-ups may provide the answer, and could be of significance in view of the widespread use of papain and other proteolytic enzymes, for example, bromelains, trypsin, etc., among biochemists and food technologists, who constantly come into contact with these enzymes in the course of their work.

We gratefully acknowledge the co-operation of Kraft Foods Ltd. We also wish to thank Dr Michael Pain for his assessment and comments on lung function, Dr A. J. Christophers for his advice and critical evaluation, and Mrs M. Griffiths who typed this paper. Dr B. McCloskey, Chief Health Officer, has kindly given permission for one of us (JEHM) to publish it.

\section{References}

Arnon, R. and Shapira, E. (1967). Antibodies to papain. Biochemistry, 6, 3942-3950.

Beecher, W. (1951). Hyperesthetic rhinitis and asthma due to digestive ferments. Illinois Medical Journal, 59, 343-344.

Cade, J. F. and Pain, M. C. F. (1971). Bronchial reactivity. Its measurement and clinical significance. Australian and New Zealand Medical Journal, 1, 22-25. and - (1973). Pulmonary function during clinical remission of asthma. Australian and New Zealand Medical Journal, 3, 545-551.

Drenth, J., Jansonius, J., Koeboek, R., Swan, H., and Wolthers, B. (1968). Structure of papain. Nature, 218, 929-932.

Flindt, M. (1969). Pulmonary disease due to inhalation of derivatives of bacillus proteus containing proteolytic enzymes. Lancet, 1, 1177-1181.

Fowler, W. S., Cornish, E. R., and Kety, S. S. (1952). Analysis of alveolar ventilation by pulmonary $\mathbf{N}_{2}$ clearance curves. Journal of Clinical Investigation, 31, 40-50.

Gandevia, B. (1970). Occupational asthma. Medical Journal of Australia, 2, 332-335.

and Mitchell, C. (1971). The dangers of proteolytic enzymes to workers. Medical Journal of Australia, 1, 1032-1033.

Goldring, I., Greenburg, L., and Ratner, I. (1968). On the production of emphysema in Syrian hamsters by aerosol inhalation of papain. Archives of Environmental Health, 16, 56-60.

Gross, P., Babyak, M. A., Tolker, E., and Kaschak, M. (1964). Enzymatically produced pulmonary emphysema. Journal of Occupational Medicine, 6, 481-484.

—, Pfitzer, E. A., Tolker, E., Babyak, M. A., and Kaschak, M. (1965). Experimental emphysema. Archives of Environmental Health, 11, 50-58.

_, de Treville, R., Babyak, M. A., Kaschak, M., and 
Tolker, E. (1968). Experimental emphysema. Archives of Environmental Health, 16, 51-58.

Holland, R. A. B. and Blacket, R. B. (1958). The carbon monoxide diffusing capacity of the lung in normal subjects. Australasian Annals of Medicine, 7, 192-204.

Hwang, C. and Ivy, S. (1951). A review of the literature of the potential therapeutic significance of papain. Annals of the New York Academy of Sciences, 54, 161-207.

Mitchell, C. (1970). Occupational asthma due to western red cedar. Medical Journal of Australia, 2, 233-235.

and Gandevia, B. (1971). Acute bronchiolitis following provocative inhalation of 'alcalase'-a proteolytic enzyme used in the detergent industry. Medical Journal of Australia, 1, 1363-1367.

Needham, C. D., Rogan, M. C., and McDonald, I. (1954). Normal standards for lung volumes, intrapulmonary gas mixing and maximum breathing capacity. Thorax, 9, 313-325.

Osgood, H. (1945). Atopic sensitivity to caroid (papain). Journal of Allergy, 16, 245-250.

Pepys, J., Hargreave, F., Longbottom, J., and Faux, J., (1969). Allergic reactions of the lungs to enzymes of bacillus subtilis. Lancet, 1, 1181-1184.

Received for publication 10 April 1974

Accepted for publication 4 June 1975

\section{The August (1975) Issue}

Comparison of in vivo effect of inorganic lead and cadmium on glutathione reductase system and $\delta$-aminolevulinate dehydratase in human erythrocytes H. A. Roels, J. P. BUCHET, R. R. LAUWERYS, AND J. SONNET

Absenteeism among survivors of the atomic bombing of Hiroshima J. W. MEIGS, W. J. BLot, S. INOUE, AND C. R. Meigs

An epidemiological study of occupational bladder tumours in the dye industry of Japan $\mathrm{K}$. TsuchIYA, T. OKUBO, AND S. IsHIZU

Determination of benzene and toluene in blood by means of a syringe-equilibration method using a small amount of blood A. Sato, T. Nakajima, and Y. Fujiwara

Chronic cyanide exposure: a clinical, radioisotope, and laboratory study A. A. El-Saharti, S. H. Ahmed, K. K. Malash, and R. Fares

S. H. El Ghawabi, M. A. GaAfar,

The ventilatory cost of activity J. E. CoTES

Adsorption of syndiotactic and isotactic poly(2-vinylpyridine 1-oxide) on quartz surface M. DoBREVA, N. Dancheva, AND P. F. Holt

Chest symptoms in farming communities with special reference to farmer's lung D. C. MORGAN, J.T. SMYTH, R. W. Lister, R. J. Pethybridge, J. C. Gilson, P. Callaghan, and G. O. Thomas

Pilot study of closing volume in byssinosis R. P. Fairman, J. Hankinson, H. Imbus, N. L. LAPP, and W. K. C. MORGAN

An evaluation of effect of airborne dust from a cotton mill on the guinea-pig ileum with reference to byssinosis F. F. Cinkotai and D. W. Franklin

Notes and miscellanea

Percivall Pott and cancer scroti M. D. KIPLING AND H. A. WALDRon

Occupational health and safety in Great Britain 1973 J. M. HARRINGTON

Book reviews

Information section

A number of copies are still available and may be obtained from the Publishing Manager, British Medical Association, Tavistock Square, London WC1H 9JR, price $£ 2 \cdot 50$ (U.S.A. \$7.50). 